\title{
Interactive comment on "Revisiting paramagnetic relaxation enhancements in slowly rotating systems: how long is the long range?" by Giovanni Bellomo et al.
}

\section{Gottfried Otting}

gottfried.otting@anu.edu.au

Received and published: 23 December 2020

The CORMA program as modified by the authors clearly is very useful. Would it be possible to install the software in the NMRbox provided by Jeffrey Hoch to make it generally accessible? This would not only be helpful for others but also increase the impact and citation rate of the present article.

While the original CORMA software was developed many years ago in the group of Tom James at UCSF, it may be possible to obtain permission to make the new version accessible in this way?

Printer-friendly version

Discussion paper 
Interactive comment on Magn. Reson. Discuss., https://doi.org/10.5194/mr-2020-33, 2020.

Interactive

comment 